\title{
Calcium-enriched Foods and Bone Mass Growth in Prepubertal Girls: A Randomized, Double-blind, Placebo-controlled Trial
}

\author{
Jean-Philippe Bonjour, ${ }^{\star}$ Anne-Lise Carrie,, Serge Ferrari, ${ }^{*}$ Helene Clavien, ${ }^{*}$ Daniel Slosman,, Gerald Theintz, ${ }^{\S}$ \\ and Rene Rizzoli* \\ *Division of Bone Diseases, formerly Division of Clinical Pathophysiology, WHO Collaborating Center for Osteoporosis and Bone \\ Disease, Department of Internal Medicine, ${ }^{\ddagger}$ Division of Nuclear Medicine, Department of Radiology, ${ }^{\S}$ Division of Biology of Growth \\ and Reproduction, Department of Pediatrics, University Hospital, Geneva; and ${ }^{\|}$Nestle Research Center, Vaud, Switzerland
}

\begin{abstract}
High calcium intake during childhood has been suggested to increase bone mass accrual, potentially resulting in a greater peak bone mass. Whether the effects of calcium supplementation on bone mass accrual vary from one skeletal region to another, and to what extent the level of spontaneous calcium intake may affect the magnitude of the response has, however, not yet been clearly established. In a doubleblind, placebo-controlled study, 149 healthy prepubertal girls aged 7.9 $\pm 0.1 \mathrm{yr}($ mean \pm SEM) were either allocated two food products containing $850 \mathrm{mg}$ of calcium (Ca-suppl.) or not (placebo) on a daily basis for $1 \mathrm{yr}$. Areal bone mineral density (BMD), bone mineral content (BMC), and bone size were determined at six sites by dual-energy x-ray absorptiometry. The difference in BMD gain between calcium-supplemented (Ca-suppl.) and placebo was greater at radial (metaphysis and diaphysis) and femoral (neck, trochanter, and diaphyses) sites (7-12 $\mathrm{mg} / \mathrm{cm}^{2}$ per yr) than in the lumbar spine $\left(2 \mathrm{mg} / \mathrm{cm}^{2}\right.$ per $\left.\mathrm{yr}\right)$. The difference in BMD gains between Ca-suppl. and placebo was greatest in girls with a spontaneous calcium intake below the median of $880 \mathrm{mg} / \mathrm{d}$. The increase in mean BMD of the 6 sites in the low-calcium consumers was accompanied by increased gains in mean $\mathrm{BMC}$, bone size, and statural height. These results suggest a possible positive effect of calcium supplementation on skeletal growth at that age. In conclusion, calcium-enriched foods significantly increased bone mass accrual in prepubertal girls, with a preferential effect in the appendicular skeleton, and greater benefit at lower spontaneous calcium intake. (J. Clin. Invest. 1997. 99:1287-1294.) Key words: bone growth - calcium-enriched foods - calcium intake • bone mineral density $\bullet$ statural height
\end{abstract}

\section{Introduction}

The bone mass accrual occurring during childhood and adolescence is a major determinant of peak bone mass, and thereby of the risk of osteoporotic fractures occurring in advanced age

Address correspondence to Prof. Jean-Philippe Bonjour, M.D., Division of Bone Diseases, formerly Division of Clinical Pathophysiology, Department of Internal Medicine, University Hospital, CH-1211 Geneva 14, Switzerland. Phone: 41-22-3729950; FAX: 41-22-3829973.

Received for publication 23 July 1996 and accepted in revised form 7 January 1997.

J. Clin. Invest.

(C) The American Society for Clinical Investigation, Inc.

0021-9738/97/03/1287/08 \$2.00

Volume 99, Number 6, March 1997, 1287-1294
(1-3). At the end of the growth period, a large variance in bone mineral density (BMD) ${ }^{1}$ and content (BMC), in either the axial or the appendicular skeleton, is observed both in healthy females and males (4-8). Many genetic and environmental factors have been suggested to influence bone mass accumulation during this period (9-15).

It is usually accepted that increasing calcium intake during childhood and adolescence can promote a greater increase in bone mass, and thereby a higher peak bone mass (16-21). Analyzing the relationship between bone mass and spontaneous calcium intake, however, indicates that not all studies (22-27) have found a positive correlation between these two variables.

Only a few prospective randomized double-blind intervention trials have examined the effects of calcium supplements in children and adolescents $(12,28-30)$. Although the results of these studies suggest that calcium supplementation can positively influence bone mass gain in this population, the magnitude of the effects appears to be different in the axial and appendicular skeleton as well as at the metaphyseal or diaphyseal levels $(12,28-30)$. Significantly, the mean bone mass gain in response to calcium supplements has been found to be only modest at the lumbar spine and proximal femur, two major sites of subsequent osteoporotic fracture $(12,28,30)$. The difficulty of consistently demonstrating a significant effect of calcium in the various parts of the skeleton may be related to differences in the osteodensitometric method used (for example, dual photon absorptiometry [DPA] $[12,28]$ versus the more precise dual-energy x-ray absorptiometry [DXA] [29]), to differences in the stage of pubertal maturation at the time of calcium supplementation $(28,29)$, or to differences in the level of spontaneous calcium intake, as observed in adult subjects (31).

We conducted a randomized, double-blind, placebo-controlled study in a homogenous cohort of prepubertal girls to assess the effects of calcium supplementation on bone mass gain at various sites of the skeleton. In the context of a largescale program for nutritional prevention during childhood of osteoporosis, as well as to anticipate the risk of low long-term compliance to pharmaceutical calcium supplements at a population level, we administered palatable calcium-enriched foods commonly taken at breakfast or as snacks to children living in an affluent western society.

\section{Methods}

Subjects and study design. The protocol was approved by the Ethical Committee of the Department of Pediatrics of the University Hospi-

1. Abbreviations used in this paper: $\mathrm{BMAD}$, bone mineral apparent density; BMC, bone mineral content; BMD, bone mineral density; Ca-suppl., calcium-supplemented; DXA, dual energy x-ray absorptiometry; ROI, region of interest. 
tal of Geneva. Informed consent was obtained from the parents and their children. Healthy prepubertal caucasian girls with a mean age $( \pm$ SEM) of $7.93 \pm 0.04 \mathrm{yr}$ (range: $6.6-9.4 \mathrm{yr}$ ) were recruited through the Public Health Youth Service of the Geneva district over an 8-mo period, from April to November, 1993. The following exclusion criteria were applied: no parental approval, ratio weight/height less than the 3rd or greater than the 97th percentile according to Geneva reference values, presence of physical signs of puberty, chronic disease, gastro-intestinal disease capable of inducing malabsorption, congenital or acquired bone disease, or regular use of medication. 149 subjects were randomized into two groups stratified according to their level of spontaneous calcium intake to avoid an uneven distribution of the low- or high-calcium consumers. A limit of $900 \mathrm{mg} / \mathrm{d}$, as assessed by an initial food frequency questionnaire, was used to determine the cutoff point for each group. For unknown reasons, the dropout rate after 4 mo of enrollment was larger (15 vs. 4 ) in one of the two experimental groups. Since for technical reasons production of the specially prepared foods could not be pursued beyond a given time, 10 out of the 149 enrolled subjects were deliberately assigned for the rest of the enrollment period to the group having shown the greater dropout rate during the first phase of the study. This explains the difference in the number of subjects enrolled between the two groups of the intention-to-treat cohort (see results). At the end of the intervention period, opening of the blinded code revealed that the larger dropout rate during the first $4 \mathrm{mo}$ was in the calcium-supplemented group.

Calcium supplement (Ca-suppl.). Calcium from milk extract was used to fortify several food products: cakes (two kinds), biscuits, fruit juices, powdered drinking chocolate, chocolate bars, and yogurts. The calcium contents (mg/serving) of calcium-enriched vs. placebo food products was as follows: chocolate cakes, 516 vs. 33; caramel cakes, 512 vs. 41 ; biscuits, 548 vs. 8 ; fruit juices, 383 vs. 11 ; powdered drinking chocolate, 530 vs. 4 ; chocolate bars, 429 vs. 80 ; yogurts, 478 vs. 174 . The corresponding phosphorus content ( $\mathrm{mg} /$ serving) were: chocolate cakes, 285 vs. 52; caramel cakes, 274 vs. 46; biscuits, 311 vs. 37; fruit juices, 73 vs. 21 ; powdered drinking chocolate, 277 vs. 26 ; chocolate bars, 252 vs. 98 ; yogurt, 304 vs. 146 . The corresponding energy contents (kcal/serving) were: chocolate cakes, 185 vs. 187; caramel cakes, 186 vs. 188 ; biscuits, 197 vs. 203; fruit juices, 120 vs. 119 ; powdered drinking chocolate, 64 vs. 60 ; chocolate bars, 270 vs. 274; yogurt, 182 vs. 180 . These foods had previously been tested for palatability and long-term tolerance in a pilot study involving a small cohort of adolescent girls. On average, the intake of two calciumenriched products per day provided a calcium supplement of about $850 \mathrm{mg}$. The control (placebo) group was given daily two similar products in terms of energy, protein, lipid and mineral content, but without added calcium. The maximal difference between the calciumenriched and placebo foods was as follows: energy, $6 \mathrm{kcal}$; proteins, $0.2 \mathrm{~g}$; lipids, $0.3 \mathrm{~g}$; carbohydrates (essentially lactose), $0.9 \mathrm{~g}$. Over the entire intervention period ( $48 \mathrm{wk}$ ) each subject received 12 sets of 56 food products ( 1 set every $4 \mathrm{wk}$ ). Parents were instructed to ensure consumption of the two food products every day in place of similar foods taken for breakfast or snacks. Compliance was recorded by the parents and verified through regular phone calls and interviews by a trained dietician (H. Clavien). Clinical examinations were conducted by a pediatrician ( $\mathrm{G}$. Theintz) at the beginning and at the end of the intervention period, with recording of anthropometric variables and assessment of pubertal status.

Calcium intake assessment. An estimate of the spontaneous calcium intake during the intervention period was obtained by averaging the results of three frequency questionnaires made at 0,24 , and $48 \mathrm{wk}$.

Measurement of bone variables. Bone mineral content (BMC, g) and areal bone mineral density $\left(\mathrm{BMD}, \mathrm{g} / \mathrm{cm}^{2}\right)$ as estimates of bone mass were determined at the beginning and the end of the study period by dual energy x-ray absorptiometry (DXA) using a Hologic QDR-2000 instrument (Waltham, MA). Six skeletal sites were assessed: distal metaphysis of the radius, diaphysis of the radius (designated respectively as the ultradistal region and as the one-third re- gion of the radial shaft according to the manufacturer's software), femoral neck, femoral trochanter, femoral diaphysis, and L2-L4 vertebrae in antero-posterior view as previously reported $(8,32)$. The coefficient of variation of repeated measurements at these sites (as determined in young healthy adults) varied between 1.0 and $1.6 \%$ from $\mathrm{BMD}$, and 0.3 to $3.0 \%$ for BMC and bone area. The possible influence of the calcium-enriched foods on skeletal size was assessed by analyzing the changes in scanned bone area $\left(\mathrm{mm}^{2}\right)$ of the six regions of interest described above. At the level of the femoral neck, the height (i.e., the dimension parallel to the hip axis) of the region of interest (ROI) rectangular box was maintained constant from one examination to the other. Only the width (i.e., the dimension perpendicular to the hip axis) was adjusted to the growth of the bone to scan a similar proportion of soft tissue on each side of the femoral neck. For the trochanter, the ROI box was maintained constant. In addition, at the level of L2-L4, the height ( $\mathrm{mm}$ ) of the region of interest was determined to be the number of lines from the lower edge of L4 to the upper edge of L2 multiplied by a conversion factor $(1$ line $=1.003$ $\mathrm{mm})$. An estimate of the mean vertebral width was derived by dividing the area by the height of L2-L4. At the level of the midfemoral shaft, the external diameter of the diaphysis was estimated by an additional analysis. A region of interest was defined at baseline as having a constant length $(45$ lines $\times 1.003=45.14 \mathrm{~mm})$ starting from the midfemoral shaft (halfway between the greater trochanter and the upper edge of the patella). To assess to what extent calcium-induced increase in areal BMD would be due to an effect on bone size as compared to volumetric mineral density, an estimate of this latter variable (bone mineral apparent density, BMAD) was calculated as previously described for lumbar spine, midradius, and femoral neck (33-34).

Follow-up after treatment discontinuation. Within the active treatment cohort, 100 girls ( 45 from the placebo and 55 from the calciumsupplemented group) underwent a third examination $1 \mathrm{yr}$ after the end of the intervention phase. Bone and anthropometric variables were measured, and calcium intake, as assessed by a fourth frequency questionnaire, was also recorded.

Expression of the results and statistical analysis. Although the intervention lasted $48 \mathrm{wk}$, the changes in the various anthropometric and osteodensitometric variables are expressed in units/yr without correction for the difference between $1 \mathrm{yr}$ and $48 \mathrm{wk}$. The differences in the anthropometric and osteodensitometric variables in the calcium-enriched and placebo groups were analyzed both in terms of active-treatment cohort, (which included the subjects who consumed the study foods during $48 \mathrm{wk}$ ) and an intention-to-treat cohort (accounting for all subjects who entered the study and had measurements redone at $48 \mathrm{wk}$ ). Bone mass gains were determined separately for each skeletal site; the average BMD changes at the six studied sites were also calculated. Results were expressed as either absolute $\left(\mathrm{g} / \mathrm{cm}^{2}\right.$ per yr) or relative terms $(\% / \mathrm{yr})$. Mean change in the bone area of the six regions of interest was also computed to assess potential changes in bone size. All results are given as mean \pm SEM. The differences between the Ca-suppl. and placebo groups were evaluated using a two-tailed Student's $t$-test for unpaired values. In addition, for the subjects on whom three measurements (at 0,48 , and $96 \mathrm{wk}$ ) were available, an ANOVA test for repeated measures was applied to evaluate whether any calcium effect observed at the end of the intervention period would be maintained one year after treatment discontinuation. Finally, a comparative analysis of the effect of Ca-suppl. on areal (BMD) vs. volumetric bone mineral density (BMAD) in radial and femoral diaphysis was made by calculating the changes in $\mathrm{Z}$ score from the mean values recorded at baseline in the intention-to-treat cohort $(n=144)$.

\section{Results}

Cohorts studied and compliance. Of the 149 prepubertal girls initially enrolled, 144 had their BMD measured at baseline and 48 wk later (intention-to-treat cohort). Among the five subjects 
Table I. Baseline Characteristics of Prepubertal Girls Assigned to Consume Foods Enriched in Calcium (Intention-to-Treat Cohort) or Not (Placebo)

\begin{tabular}{lcc}
\hline & Placebo & $\begin{array}{c}\text { Calcium } \\
\text { supplemented }\end{array}$ \\
\hline No. of subjects & 67 & 77 \\
Age $(\mathrm{yr})$ & $7.94 \pm 0.06$ & $7.92 \pm 0.06$ \\
Height $(\mathrm{cm})$ & $127.5 \pm 0.7$ & $128.1 \pm 0.7$ \\
Weight $(\mathrm{kg})$ & $26.8 \pm 0.5$ & $26.4 \pm 0.4$ \\
Radial metaphysis BMD $\left(\mathrm{g} / \mathrm{cm}^{2}\right)$ & $301 \pm 4$ & $295 \pm 3$ \\
Radial diaphysis BMD $\left(\mathrm{g} / \mathrm{cm}^{2}\right)$ & $431 \pm 4$ & $436 \pm 3$ \\
Femoral neck BMD $\left(\mathrm{g} / \mathrm{cm}^{2}\right)$ & $622 \pm 9$ & $642 \pm 8$ \\
Femoral trochanter BMD $\left(\mathrm{g} / \mathrm{cm}^{2}\right)$ & $498 \pm 7$ & $510 \pm 6$ \\
Femoral diaphysis BMD $\left(\mathrm{g} / \mathrm{cm}^{2}\right)$ & $1026 \pm 10$ & $1028 \pm 10$ \\
Lumbar spine $(\mathrm{L} 2-\mathrm{L} 4) \mathrm{BMD}\left(\mathrm{g} / \mathrm{cm}^{2}\right)$ & $616 \pm 7$ & $617 \pm 8$ \\
& & \\
\hline
\end{tabular}

All values are given as mean \pm SEM. Areal BMD values are in $\mathrm{mg} / \mathrm{cm}^{2}$. None of the differences between means recorded in the calcium-supplemented and the placebo groups were found to be statistically significant at $P<0.1$.

who declined to be examined at the end of the 1-yr interval, three belonged to the Ca-suppl. group, and two to the placebo group. At baseline no difference between the two groups was found with respect to age, statural height, body weight, or BMD at any skeletal site (Table I). From the initial cohort, 108 girls remained compliant (active-treatment cohort) to the study food products over the whole study period. Among the 41 subjects $(28 \%)$ who dropped out from the study, 40 reported lassitude with the consumption of two imposed food products per day, and one left the Geneva district. Dropout times after the onset of the intervention phase ranged from 4 to $32 \mathrm{wk}$ (mean, $15.3 \pm 1.6 \mathrm{wk}, n=25$ ) and 4 to $28 \mathrm{wk}$ (mean, $13.0 \pm 2.1 \mathrm{wk}, n=16$ ) in the Ca-suppl. and placebo groups, respectively. In the active-treatment cohort, $89.9 \pm 1.4 \%(n=55)$ and $90.2 \pm 1.4 \%(n=53)$ of the study foods were consumed throughout the intervention period in the Ca-suppl. and placebo groups, respectively, as estimated by regular interviews of the subjects' mothers. After 48 wk, none of the examined subjects displayed any sign of puberty.

Calcium intake. Spontaneous calcium intake, as determined by three frequency questionnaires at 16-wk intervals, were similar in both groups $(916 \pm 42$, and $879 \pm 36 \mathrm{mg} / \mathrm{d}$ in Ca-suppl. and placebo groups, respectively). Taking into account the individual compliance over the 48-wk intervention period, the mean daily amount of supplemented calcium ingested with the enriched foods was $807 \pm 10 \mathrm{mg}$. Thus, the calcium intake increased from $916 \pm 42$ to $1723 \pm 44 \mathrm{mg} / \mathrm{d}$ in the Ca-suppl. group.

Anthropometric and bone mass changes. Table II shows the anthropometric and osteodensitometric values recorded in the active-treatment groups after a 1-y interval. At baseline, the mean values in the Ca-suppl. and the placebo groups did not differ between the two groups, and were similar to those of the intention-to-treat groups presented in Table I. The increases in statural height, body weight, and BMD at the various skeletal sites in the placebo group were within the expected range for prepubertal girls of this age, and were all statistically significant $(P<0.001$ by two-sided paired sample analysis). The corresponding BMD gains calculated in either absolute $\left(\mathrm{mg} / \mathrm{cm}^{2}\right.$ per $\left.\mathrm{yr}\right)$ or relative $(\% / \mathrm{yr})$ terms are presented in Table II and Fig. 1, respectively. At all sites, the mean increment in bone mass was greater in the Ca-suppl. than in the placebo group. However, the difference in BMD was smaller in the lumbar spine than in the radial and femoral sites. The magnitude of the calcium effect, further estimated as the ratio of the mean bone mass gain in the Ca-suppl. group over that observed in the placebo group ( $\Delta$ Ca-suppl. $/ \Delta$ placebo) (Table II), ranged from 1.09 to 1.78 (mean of six measured skeletal sites, 1.52). Interestingly, the $\Delta \mathrm{Ca}$-suppl. $/ \Delta$ placebo ratio for lumbar spine BMD was quite similar to that calculated for height gain. In contrast to all osteodensitometric variables and to statural height, the mean change in either body weight or BMI was not greater in the Ca-suppl. group than in the placebo group (Table II).

Table II. Anthropometric and Osteodensitometric Values Determined at Baseline and 48 Wk Later in Prepubertal Girls Consuming Foods Enriched or Not in Calcium (Active-Treatment Cohort)

\begin{tabular}{|c|c|c|c|c|c|c|c|}
\hline & \multicolumn{2}{|c|}{$\begin{array}{c}\text { Placebo } \\
n=53\end{array}$} & \multirow[b]{2}{*}{ Gain } & \multicolumn{2}{|c|}{$\begin{array}{l}\text { Calcium supplemented } \\
\quad n=55\end{array}$} & \multirow[b]{2}{*}{ Gain } & \multirow{2}{*}{$\begin{array}{c}\Delta \text { Ca suppl. } \\
\Delta \text { Placebo }\end{array}$} \\
\hline & Baseline & $48 \mathrm{wk}$ & & Baseline & $48 \mathrm{wk}$ & & \\
\hline Age (yr) & $7.94 \pm 0.07$ & $8.92 \pm 0.07$ & & $7.94 \pm 0.07$ & $8.93 \pm 0.08$ & & \\
\hline Height $(\mathrm{cm})$ & $127.2 \pm 0.8$ & $132.2 \pm 0.8$ & $5.0 \pm 0.1$ & $128.8 \pm 0.9$ & $134.1 \pm 0.9$ & $5.4 \pm 0.1$ & 1.08 \\
\hline Weight (kg) & $26.9 \pm 0.6$ & $30.6 \pm 0.7$ & $3.7 \pm 0.2$ & $26.9 \pm 0.6$ & $30.4 \pm 0.7$ & $3.4 \pm 0.1$ & 0.95 \\
\hline $\operatorname{BMI}\left(\mathrm{kg} / \mathrm{m}^{2}\right)$ & $16.6 \pm 0.3$ & $17.4 \pm 0.3$ & $0.8 \pm 0.1$ & $16.2 \pm 0.2$ & $16.8 \pm 0.2$ & $0.6 \pm 0.1$ & 0.88 \\
\hline Radial metaphysis BMD $\left(\mathrm{g} / \mathrm{cm}^{2}\right)$ & $299 \pm 4$ & $308 \pm 4$ & $9 \pm 2$ & $296 \pm 3$ & $312 \pm 4$ & $16 \pm 3 *$ & 1.78 \\
\hline Radial diaphysis BMD (g/ $\left.\mathrm{cm}^{2}\right)$ & $429 \pm 4$ & $442 \pm 4$ & $13 \pm 2$ & $437 \pm 4$ & $457 \pm 4$ & $20 \pm 2^{\S}$ & 1.54 \\
\hline Femoral neck BMD $\left(\mathrm{g} / \mathrm{cm}^{2}\right)$ & $622 \pm 9$ & $635 \pm 9$ & $13 \pm 4$ & $635 \pm 9$ & $656 \pm 11$ & $22 \pm 4$ & 1.69 \\
\hline Femoral trochanter BMD $\left(\mathrm{g} / \mathrm{cm}^{2}\right)$ & $499 \pm 7$ & $514 \pm 8$ & $15 \pm 3$ & $506 \pm 7$ & $530 \pm 8$ & $25 \pm 4^{\ddagger}$ & 1.79 \\
\hline Femoral diaphysis BMD $\left(\mathrm{g} / \mathrm{cm}^{2}\right)$ & $1024 \pm 11$ & $1077 \pm 12$ & $54 \pm 4$ & $1032 \pm 12$ & $1098 \pm 13$ & $66 \pm 3^{\|}$ & 1.22 \\
\hline Lumbar spine (L2-L4) BMD $\left(\mathrm{g} / \mathrm{cm}^{2}\right)$ & $615 \pm 8$ & $638 \pm 8$ & $23 \pm 3$ & $622 \pm 10$ & $647 \pm 10$ & $25 \pm 3$ & 1.09 \\
\hline
\end{tabular}

All values are given as mean \pm SEM. Areal BMD values are in $\mathrm{mg} / \mathrm{cm}^{2}$. All values recorded at $48 \mathrm{wk}$ were statistically significant as compared to baseline values at $P<0.001$ by two-sided paired Student's $t$-test analysis. $\Delta$ Ca suppl. / $\Delta$ Placebo values correspond to the ratio of the gains in the calcium supplemented over that in the placebo group as calculated from the means of the individual differences recorded at 48 wk and at baseline. $* P<0.08$, ${ }^{\ddagger} P<0.05,{ }^{\S} P<0.02, \| P<0.01$ as compared to the corresponding change in the placebo group. 

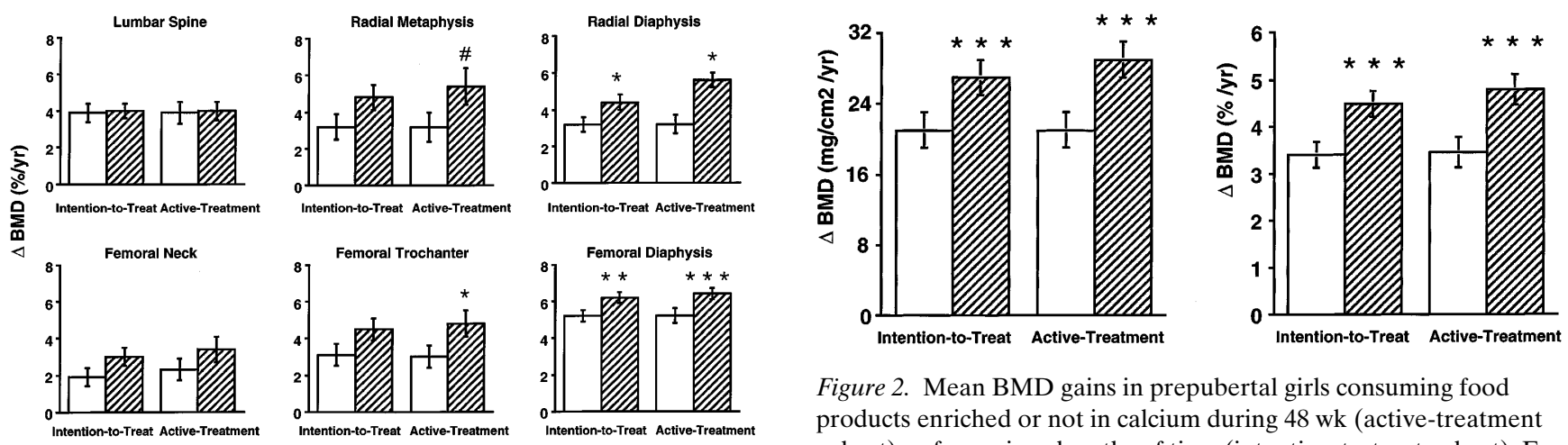

Figure 1. BMD gains in prepubertal girls consuming food products enriched or not in calcium during $48 \mathrm{wk}$ (active-treatment cohort) or for various lengths of time (intention-to-treat cohort). Bars represent means \pm SEM. The number of subjects in the active-treatment cohort was as follows: placebo (open bars) $=53$, Calcium-Supplemented $($ dashed bars $)=55$. In the intention-to-treat cohort, numbers were: placebo $($ open bars $)=67$, calcium-supplemented $($ dashed bars $)=77$ ${ }^{\#} P<0.08 ; * P<0.05 ; * * P<0.02 ; * * * P<0.01$.

The mean increment in BMD for the six measured skeletal sites, as expressed in both absolute and relative terms, is illustrated in Fig. 2. The difference between the Ca-suppl. and placebo groups was highly significant in both the active-treatment and intention-to-treat cohorts. The effect on mean BMD gain remained highly significant $(P<0.02)$, even after adjustment for age, height, and weight at entry (data not shown). The corresponding mean increases in both $\mathrm{BMC}$ and bone area were also greater in the Ca-suppl. group than in the placebo group, but did not reach statistical significance (data not shown). In the Ca-suppl. subjects belonging to the intention-to-treat cohort, the change in mean BMD of the six skeletal sites was pos-

itively correlated $(r=0.24, P=0.038, n=77)$ with the cumulative amount of calcium ingested from the enriched foods.

Effects of calcium supplements in relation to spontaneous calcium intake. To evaluate the effects of calcium-enriched foods on bone mass gain in relation to spontaneous calcium intake (as assessed by averaging the results from the food frequency questionnaires made at 0,24 , and $48 \mathrm{wk}$ ), the Ca-suppl. and placebo groups were divided in two subgroups according to the median of their spontaneous calcium intake ( 855 and $880 \mathrm{mg} / \mathrm{d}$ in the intention-to-treat and active-treatment cohorts, respectively). At baseline, there was no statistically significant difference between the Ca-suppl. and placebo groups

Table III. Changes in Anthropometric Variables, BMD, BMC and Bone Size in Response to Calcium-Enriched Foods in Prepubertal Girls Distributed According to their Spontaneous Calcium Intake

\begin{tabular}{|c|c|c|c|c|c|c|c|c|}
\hline \multirow{3}{*}{$\begin{array}{l}\text { Spontaneous } \\
\text { calcium intake }\end{array}$} & \multicolumn{4}{|c|}{ Intention-to-treat cohort } & \multicolumn{4}{|c|}{ Active-treatment cohort } \\
\hline & \multicolumn{2}{|c|}{$<$ median $^{\mathrm{a}}$} & \multicolumn{2}{|c|}{$>$ median } & \multicolumn{2}{|c|}{$<$ median $^{\mathrm{a}}$} & \multicolumn{2}{|c|}{$>$ median } \\
\hline & Placebo & Ca suppl. & Placebo & Ca suppl. & Placebo & Ca suppl. & Placebo & Ca suppl. \\
\hline & $n=36$ & $n=36$ & $n=31$ & $n=41$ & $n=29$ & $n=25$ & $n=24$ & $n=30$ \\
\hline $\begin{array}{l}\text { Calcium intake } \\
\quad(\mathrm{mg} / \mathrm{d})\end{array}$ & $694 \pm 16$ & $1238 \pm 56$ & $1175 \pm 64$ & $1805 \pm 54^{\|}$ & $711 \pm 19$ & $1441 \pm 34 \|$ & $1224 \pm 76$ & $1958 \pm 42^{\|}$ \\
\hline $\begin{array}{l}\Delta \text { Height } \\
(\mathrm{cm} / \mathrm{yr})\end{array}$ & $4.7 \pm 0.2$ & $5.2 \pm 0.2^{*}$ & $5.3 \pm 0.2$ & $5.1 \pm 0.2$ & $4.8 \pm 0.2$ & $5.4 \pm 0.3 *$ & $5.3 \pm 0.2$ & $5.3 \pm 0.2$ \\
\hline $\begin{array}{r}\Delta \text { Weight } \\
(\mathrm{kg} / \mathrm{yr})\end{array}$ & $3.2 \pm 0.2$ & $3.3 \pm 0.2$ & $3.8 \pm 0.3$ & $3.3 \pm 0.2$ & $3.4 \pm 0.3$ & $3.6 \pm 0.3$ & $3.9 \pm 0.3$ & $3.3 \pm 0.3$ \\
\hline $\begin{array}{l}\Delta \mathrm{BMD} \\
\left(\mathrm{mg} / \mathrm{cm}^{2} / \mathrm{yr}\right)\end{array}$ & $19 \pm 2$ & $27 \pm 2^{\|}$ & $23 \pm 2$ & $27 \pm 2$ & $19 \pm 3$ & $30 \pm 3^{\S}$ & $23 \pm 2$ & $28 \pm 3$ \\
\hline $\begin{array}{l}\Delta \mathrm{BMC} \\
(\mathrm{mg} / \mathrm{yr})\end{array}$ & $604 \pm 40$ & $729 \pm 44^{\ddagger}$ & $685 \pm 43$ & $694 \pm 35$ & $610 \pm 43$ & $753 \pm 58^{\ddagger}$ & $669 \pm 51$ & $705 \pm 36$ \\
\hline $\begin{array}{c}\Delta \text { Bone area } \\
\left(\mathrm{mm}^{2} / \mathrm{yr}\right)\end{array}$ & $58.7 \pm 3.7$ & $67.8 \pm 2.8^{\ddagger}$ & $64.7 \pm 4.1$ & $62.9 \pm 3.2$ & $59.5 \pm 4.1$ & $68.5 \pm 3.5$ & $63.4 \pm 4.7$ & $63.9 \pm 2.8$ \\
\hline
\end{tabular}

Values are given as mean \pm SEM. ${ }^{a}$ The median of the spontaneous dairy calcium intake was 855 and 880 in the intention-to-treat and active-treatment cohorts, respectively. BMD, BMC, and bone area values are the means of the six skeletal sites presented in Table IV and averaged in each subject. The total calcium intake corresponds to the sum of the dairy calcium taken spontaneously and of calcium in the enriched food products. $* P \leq 0.08$, ${ }^{\ddagger} P \leq 0.05,{ }^{\circledR} P \leq 0.02, \| P \leq 0.01$ as compared to the corresponding placebo group. 


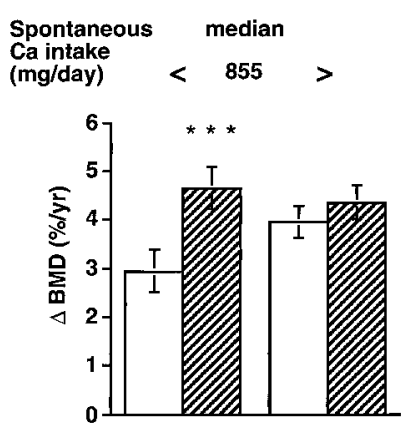

Intention-to-Treat

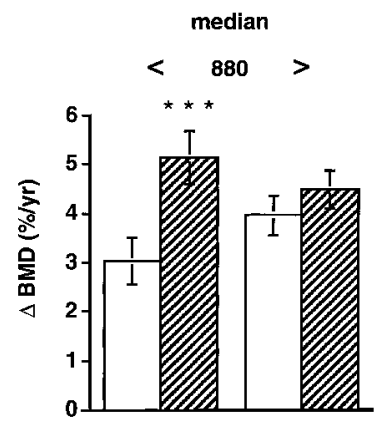

Active-Treatment
Figure 3. Changes in BMD in response to calcium-enriched foods in prepubertal girls distributed according to their spontaneous calcium intake. Bars represent means \pm SEM. BMD values are the mean of the 6 skeletal sites. The corresponding absolute changes in BMD are presented in Table III. The median spontaneous calcium intake is indicated above the bars. The mean spontaneous calcium intake was $650 \pm 16$ and $1143 \pm 33 \mathrm{mg} / \mathrm{d}$ in the intention-to-treat cohort, and $675 \pm 17$ and $1185 \pm 39 \mathrm{mg} / \mathrm{d}$ in the active-treatment cohort. *** $P \leq$ 0.01 as compared to the corresponding placebo group.

in terms of BMD at any site (data not shown); this was observed in both the spontaneously low- and high-calcium intake groups, which had mean calcium intakes of $650 \pm 33(n=72)$ and $1143 \pm 33 \mathrm{mg} / \mathrm{d}(n=72)$, respectively. Both statural height and body weight, however, were significantly greater among the spontaneously high- versus low-calcium consumers (129.1 \pm 0.7 vs. $126.5 \pm 0.7 \mathrm{~cm}, P<0.001 ; 27.5 \pm 0.5$ vs. $25.7 \pm 0.5$ $\mathrm{kg}, P<0.001$, respectively). The mean BMD gain in response to calcium supplements, as expressed in absolute (Table III) or relative (Fig. 3) terms, was more pronounced among the lowcalcium consumers ( $\Delta$ Ca-suppl. / $\Delta$ placebo: $1.42-1.58 \mathrm{~g} / \mathrm{cm}^{2}$, depending on the site examined). Indeed, linear regression analysis showed that the mean BMD gain at the six skeletal sites was significantly correlated to the total calcium consump- tion in the spontaneously low $(r=0.32, P<0.007)$, but not in the high-calcium intake subgroups of the intention-to-treat cohort $(r=0.02$, NS).

Effect of calcium on BMC, skeletal size, and statural height. As shown in Table III, there were also significant increments in both mean BMC ( $\Delta$ Ca-suppl / $\Delta$ placebo ratio, 1.21-1.23) and mean bone area of the six investigated skeletal sites $(\Delta \mathrm{Ca}$ suppl. / $\Delta$ placebo ratio, 1.15-1.16) in the subgroup of lowcalcium consumers. The change in mean bone size was accompanied by a trend toward greater statural height gain $(\Delta$ Ca-suppl. / $\Delta$ placebo ratio, 1.11-1.13) which nearly achieved statistical significance. Indeed, the reduced gain in bone area and statural height observed in the spontaneously low- versus high-calcium consumers appeared to be corrected by the calcium-enriched foods (Table III).

A similar pattern was observed in the projected area of the lumbar spine, and further morphometric analysis indicated that in the spontaneously low-calcium intake subgroup, the vertebral height gain at L2-L4 was significantly greater in the Ca-suppl. than in the placebo group (Table IV). At the level of the femoral midshaft, a significant difference in width change was also observed between the Ca-suppl. and the placebo groups in the spontaneously low-calcium intake subgroup (Table 4).

To evaluate whether the calcium effect on bone mass was associated with a commensurate increase in volumetric mineral density, gain in $\mathrm{Z}$ scores from baseline values was calculated for both BMD and BMAD at the level of the radial and femoral diaphyses, two sites where the response was particularly significant. In the low-calcium consumers of the active treatment cohort presented in Table III, the difference in BMD Z score gain between the two groups was greater $(\mathrm{Ca}-$ suppl. $[n=29]$ minus placebo $[n=25]=+0.28$ and +0.18 , $P<0.05$, in radial and femoral diaphysis, respectively) than that in BMAD Z score (Ca-suppl. minus placebo $=+0.05$ and $+0.08, P>0.1$, in radial and femoral diaphysis, respectively).

Follow-up 1 yr after treatment termination. 100 girls (Casuppl., $n=55$; placebo, $n=45$ ) out of the 108 in the active treatment cohort were followed up to $1 \mathrm{yr}$ after they stopped

Table IV. Changes at the Level of the Lumbar Spine and Midfemoral Shaft at the End of the Intervention ( $\Delta 2-1)$ and 1 yr After Discontinuation of the Treatment (43-1) in Girls Having a Spontaneously Low Calcium Intake

\begin{tabular}{|c|c|c|c|c|}
\hline & \multicolumn{2}{|c|}{$\Delta 2-1$} & \multicolumn{2}{|c|}{$\Delta 3-1$} \\
\hline & Placebo & Ca suppl. & Placebo & Ca suppl. \\
\hline & $n=24$ & $n=25$ & $n=24$ & $n=25$ \\
\hline \multicolumn{5}{|l|}{ Lumbar spine } \\
\hline$\Delta$ Bone area $\left(\mathrm{mm}^{2} / \mathrm{yr}\right)$ & $139 \pm 20$ & $181 \pm 15$ & $339 \pm 23$ & $391 \pm 41$ \\
\hline$\Delta$ Width $(\mathrm{mm} / \mathrm{yr})$ & $0.8 \pm 0.3$ & $0.8 \pm 0.2$ & $2.2 \pm 0.2$ & $2.1 \pm 0.3$ \\
\hline$\Delta$ Height $(\mathrm{mm} / \mathrm{yr})$ & $2.4 \pm 0.3$ & $3.6 \pm 0.3^{\ddagger}$ & $5.0 \pm 0.4$ & $6.2 \pm 0.5^{\ddagger}$ \\
\hline$\Delta \mathrm{BMC}(\mathrm{mg} / \mathrm{yr})$ & $1302 \pm 182$ & $1781 \pm 198$ & $3570 \pm 250$ & $4257 \pm 541$ \\
\hline$\Delta \mathrm{BMD}\left(\mathrm{mg} / \mathrm{cm}^{2} / \mathrm{yr}\right)$ & $16 \pm 4$ & $23 \pm 5$ & $51 \pm 5$ & $59 \pm 8$ \\
\hline \multicolumn{5}{|l|}{ Femoral shaft } \\
\hline$\Delta$ Bone area $\left(\mathrm{mm}^{2} / \mathrm{yr}\right)$ & $17 \pm 4$ & $28 \pm 4 *$ & $50 \pm 6$ & $64 \pm 6^{*}$ \\
\hline$\Delta$ Width $(\mathrm{mm} / \mathrm{yr})$ & $0.4 \pm 0.1$ & $0.6 \pm 0.1^{\ddagger}$ & $1.1 \pm 0.1$ & $1.4 \pm 0.1^{\ddagger}$ \\
\hline$\Delta \mathrm{BMC}(\mathrm{mg} / \mathrm{yr})$ & $645 \pm 68$ & $886 \pm 60^{\S}$ & $1676 \pm 98$ & $2008 \pm 120^{\S}$ \\
\hline$\Delta \mathrm{BMD}\left(\mathrm{mg} / \mathrm{cm}^{2}\right.$ per $\left.\mathrm{yr}\right)$ & $58 \pm 6$ & $73 \pm 5^{*}$ & $139 \pm 9$ & $156 \pm 8^{*}$ \\
\hline
\end{tabular}

Values are mean \pm SEM recorded in girls having had a third examination $1 \mathrm{yr}$ after treatment discontinuation (active-treatment cohort). All gains were statistically significant by paired $t$-test analysis. ${ }^{*} P<0.08,{ }^{\ddagger} P \leq 0.05,{ }^{\S} P \leq 0.02$ as compared to the placebo group using an ANOVA test for repeated measures. 
the consumption of the study foods. Most of the absolute differences in mean bone mass and size gains recorded at the end of the intervention period was still detectable $1 \mathrm{yr}$ after termination of the dietary intervention (mean BMD, $58 \pm 3$ vs. $53 \pm 3$ $\mathrm{mg} / \mathrm{cm}^{2}, P<0.05$; mean BMC, $1265 \pm 66$ vs. $1136 \pm 56 \mathrm{mg}, P=$ 0.101 ; mean bone area, $143 \pm 6$ vs. $131 \pm 5 \mathrm{~mm}^{2}, P<0.08$; statural height, $11.9 \pm 0.3$ vs. $11.2 \pm 0.3 \mathrm{~cm}, P=0.09$, in the Ca-suppl. and placebo groups, respectively, ANOVA test for repeated measurement). Among the 100 girls who underwent a third examination, 49 belonged to the group of spontaneously low-calcium consumers in whom the effects of the calcium-enriched foods on BMD, BMC, scanned bone area and statural height had been particularly significant. At the levels of the lumbar spine and femoral midshaft, the differences in height and width gain, observed at the end of the intervention period were still statistically significant $1 \mathrm{yr}$ after treatment discontinuation (Table IV).

\section{Discussion}

A recently held National Institutes of Health Consensus Development Conference concluded that a calcium intake above the Recommended Dietary Allowance (RDA) of $800 \mathrm{mg} / \mathrm{d}$ may lead to an increased rate of bone accumulation in children aged 6-10 yr (35). This report underlined the necessity to consider the effects of calcium on regional changes in bone mass, and recommended the improvement of strategies to achieve and maintain optimal dietary intake of calcium by both nutritional and supplemental means (35). It is appropriate to discuss the present study in relation to these considerations.

Compliance rate. In the present study, the compliance rate was about $75 \%$ after 1 yr. A higher rate could have been anticipated, considering that calcium was supplemented using enriched palatable foods usually taken at either breakfast or as snacks, and known to be well accepted by children. The psychological constraint on the families involved in controlled trials, however, and the fact that they were blinded with respect to the study product, played an important role in this phenomenon.

Changes in BMD gains. Overall, our results indicate that increasing calcium intake from approximately 900 to $1750 \mathrm{mg} / \mathrm{d}$ led to a substantial increment, 3.5 to $5.0 \% / y r$ (Fig. 2), in the rate of bone mass accumulation in prepubertal girls. The appendicular sites appeared to be more responsive than the axial skeleton. Indeed, the effect was found to be minimal in the lumbar spine, as assessed by measuring spinal BMD in the classical antero-posterior view. Among the appendicular regions, the most obvious positive effects were observed at sites essentially consisting of cortical bone (e.g., radial and femoral diaphysis). Nevertheless, BMD gain was also positively influenced by calcium supplementation at the trochanter and femoral neck levels as well as at the radial metaphysis. So far, only one placebo-controlled study has compared the effects of calcium supplementation at different sites of the skeleton in 22 twin pairs of prepubertal female and male children (28). The most prominent effects were also observed in the appendicular skeleton at the level of the midshaft radius, with weaker responses at the levels of lumbar spine $(<1.0 \% / y r)$ and proximal femur. In this region, the calcium effect did not achieve statistical significance, despite a longer (3 yr) duration of the intervention. Similarly, in a study undertaken in prepubertal Chinese girls, calcium supplements were associated with a higher radial BMD gain (30). Taken together, these results (as well as other studies in experimental animals [36] and human subjects $[37,38]$ ) suggest that the appendicular skeleton, (particularly regions predominantly composed of compact bone) appear to be more sensitive than the axial skeleton to the effect of calcium supplementation above RDA. Importantly, however, calcium supplementation appears also to have an effect on BMC and bone size at the level of the lumbar spine. Therefore, the use of only areal BMD in the classical DPA/DXA antero-posterior view may well underestimate the effect of calcium supplementation on the axial skeleton during growth.

Spontaneous calcium intake and response to calcium supplements. A thorough meta-analysis of calcium balance data recently indicated that there is a threshold level of calcium intake in humans (39), as previously demonstrated in animal experiments (40). In children and adolescents, the level above which a rise in calcium intake is no longer associated with an increase in calcium retention appears to be set between 1200 to $1500 \mathrm{mg} / \mathrm{d}$ (39). Accordingly, our study clearly indicates that the response to calcium supplementation in terms of bone mass gain was markedly dependent on the level of spontaneous calcium intake. Indeed, the benefit was 3.5 -fold (2.1 vs. $0.6 \% / y r)$ greater in the spontaneously low- (e.g., less than 850 $\mathrm{mg} / \mathrm{d}$ ) versus high-calcium consumers. Our data suggest that a calcium intake below $800-900 \mathrm{mg} / \mathrm{d}$ may not be sufficient for optimal bone mass accrual in 7-9 yr-old prepubertal girls. On the other hand, the effect of calcium supplementation appears to be rather mild at that age when the spontaneous consumption is larger than $1100-1200 \mathrm{mg} / \mathrm{d}$. To our knowledge, this is the first evidence from a placebo-controlled study showing that there is a calcium intake threshold below which supplementation can be particularly beneficial to prepubertal children. A review of controlled clinical trials testing the effect of calcium supplementation on BMD in postmenopausal women also indicated a greater benefit in low-calcium consumers (41). Our results suggest that the use of a simple frequency questionnaire could be useful for identifying children who would particularly benefit from an increased calcium intake.

Mechanisms of the effects of calcium supplements. The positive effects of calcium previously reported in double-blind, placebo-controlled clinical trials carried out in prepubertal children $(28,30)$ have essentially been ascribed to a reduction in bone remodeling (42). In favor of this notion was the fact that the level of serum osteocalcin, a biochemical marker of bone remodeling in adults, was significantly reduced in the calciumsupplemented prepubertal group (28). Such an explanation is compatible with the currently favored mechanism proposed to account for the inhibitory effect of calcium on age-related bone loss $(31,41,43-46)$.

In the two aforementioned studies, the positive bone mass effect of calcium (given as either citrate malate or carbonate salts) was not associated with any change in either bone area or statural height $(28,30)$. Our study was not aimed at elucidating the mechanism of calcium effect on bone mass. Consequently, and to maintain the compliance level as high as possible, the protocol did not include any blood or urine sampling. Nevertheless, careful examination of the changes in scanned bone area and in statural height suggests that calcium supplementation, as provided in our study, could affect bone modeling. Indeed, in the group of spontaneous low-calcium consumers, calcium-enriched foods enhanced the gain of both mean scanned bone area and statural height to the level achieved in 
the spontaneously high-calcium consumers. Morphometric analysis of the changes observed in the lumbar spine and in femoral diaphysis suggests that calcium could enhance both the longitudinal and the cross-sectional growth of the bones. As reviewed by Nordin (4), the possibility that milk calcium may positively influence longitudinal growth has been suspected for several decades. In many studies it was difficult to discriminate between the effects of calcium from those of milkcontained proteins or energy. In the present study, both calcium-enriched and placebo food products provided identical amounts of proteins and energy. Thus, the possibility that milk calcium may affect not only the remodeling, but also the modeling of the skeleton, deserves to be further investigated. As previously indicated, the tested foods were enriched with calcium from milk extract. With the daily consumption of two tested foods, the mean difference in the phosphorus intake was $386 \mathrm{mg} / \mathrm{d}$ as compared to $870 \mathrm{mg} / \mathrm{d}$ mean difference of calcium. Based on previous dietary diary recording in prepubertal girls of that age (47), one can estimate that the enriched foods increased the intake of phosphorus by $30-35 \%$ as compared to a $100 \%$ increase for calcium intake. To what extent this increase in the phosphorus intake played a contributing role in the stimulation of bone mass accrual reported in this study remains to be determined.

An important issue is whether the positive effect on bone mass gain will be sustained after discontinuation of calcium supplementation, and thus be ultimately translated into higher peak bone mass. As mentioned above, our data suggest that milk calcium supplementation may increase bone mass not only by inhibiting the process of remodeling, but also by stimulating bone modeling. According to this hypothesis one may expect that the contribution of the modeling effect on bone mass will not completely disappear after discontinuation of the calcium supplementation. Indeed, our data suggest that part of the gain in bone mass and bone size was not lost $1 \mathrm{yr}$ after the end of the calcium supplementation. Further prospective longterm studies will eventually provide a definite answer to the question of whether or not a transient rise in the intake of calcium during growth can permanently increase the amount of bone tissue through a modeling effect in certain parts of the skeleton.

In summary, calcium-enriched food given to prepubertal girls with a spontaneous calcium intake below RDA significantly increased bone mass gain at several sites of the appendicular skeleton, including the proximal femur. Morphometric analysis provided evidence for a calcium effect on bone modeling which was associated with an increase in statural growth.

\section{Acknowledgments}

We are indebted to Dr. P. Hazeghi, M.D., and to the Geneva Public Youth Service for the recruitment of the subjects, to the team of the bone densitometry unit, and to Mrs. S. Gardiol, C. Ang and M.-C. Brandt for their help in preparing the manuscript.

This work was supported by Nestec Ltd., Lausanne, Switzerland, and by the Swiss National Science Foundation (grants 32-32415.91 and 31-40758.94).

\section{References}

1. Riggs, B.L., and L.J. Melton III. 1988. Osteoporosis. Etiology, Diagnosis, and Management. Raven Press, New York.
2. Hui, S.L., C.W. Slemenda, and C.C. Johnston, Jr. 1990. The contribution of bone loss to postmenopausal osteoporosis. Osteoporosis Int. 1:30-34.

3. Johnston, C.C., Jr., and C. Longcope. 1990. Premenopausal bone loss - a risk factor for osteoporosis. N. Engl. J. Med. 323:1271-1272.

4. Nordin, B.E.C. 1976. Calcium, phosphate, and magnesium metabolism. Clinical Physiology and Diagnostic Procedures. Churchill Livingstone, Edinburgh, London, and New York.

5. Hui, S.L., C.C. Johnston, Jr., and R.B. Mazess. 1985. Bone mass in normal children and young adults. Growth. 49:34-43.

6. Pollitzer, W.S., and J.J.B. Anderson. 1989. Ethnic and genetic differences in bone mass: a review with a hereditary vs. environmental perspective. Am. J. Clin. Nutr. 50:1244-1259.

7. Ott, S.M. 1990. Attainment of peak bone mass. J. Clin. Endocrinol. Metab. 71:1082A-1082C.

8. Bonjour, J.P., G. Theintz, B. Buchs, D. Slosman, and R. Rizzoli. 1991. Critical years and stages of puberty for spinal and femoral bone mass accumulation during adolescence. J. Clin. Endocrinol. \& Metab. 73:555-563.

9. Pocock, N.A., J.A. Eisman, J.L. Hopper, M.G. Yeates, P.N. Sambrook, and S. Eberl. 1987. Genetic determinants of bone mass in adults - a twin study. J. Clin. Invest. 80:706-710.

10. Seeman, E., J.L. Hopper, L.A. Bach, M.E. Cooper, E. Parkinson, J. McKay, and G. Jerums. 1989. Reduced bone mass in daughters of women with osteoporosis. N. Engl. J. Med. 320:554-558.

11. Tylavsky, F.A., A.D. Bortz, R.L. Hancock, and J.J.B. Anderson. 1989 Familial resemblance of radial bone mass between premenopausal mothers and their college-age daughters. Calcif. Tissue Int. 45:265-272.

12. Matkovic, V., D. Fontana, C. Tominac, P. Goel, and C.H. Chesnut III 1990. Factors that influence peak bone mass formation: A study of calcium balance and the inheritance of bone mass in adolescent females. Am. J. Clin. Nutr. 52:878-888.

13. Lutz, J., and R. Tesar. 1990. Mother-daughter pairs: spinal and femoral bone densities and dietary intakes. Am. J. Clin. Nutr. 52:872-877.

14. Bachrach, L.K., P.A. Guido, D. Katzman, I.F. Litt, and R. Marcus. 1990 Decreased bone density in adolescent girls with anorexia nervosa. Pediatrics. 86:440-447.

15. Bell, N.H., J. Shary, J. Stevens, M. Garza, L. Gordon, and J. Edwards. 1991. Demonstration that bone mass is greater in black than in white children. J. Bone Miner. Res. 6:719-723.

16. Sandler, R.B., C.W. Slemenda, R.E. LaPorte, J.A. Cauley, M.M. Schramm, M.L. Barresi, and A.M. Kriska. 1985. Postmenopausal bone density and milk consumption in childhood and adolescence. Am. J. Clin. Nutr. 42:270274.

17. Chan, G. 1991. Dietary calcium and bone mineral status of children and adolescents. Am. J. Dis. Child. 145:631-634.

18. Sentipal, J.M., G.M. Wardlaw, J. Mahan, and V. Matkovic. 1991. Influence of calcium intake and growth indexes on vertebral bone mineral density in young females. Am. J. Clin. Nutr. 54:425-428.

19. Tylavsky, F.A., J.J.B. Anderson, R.V. Talmage, and T.N. Taft. 1992. Are calcium intakes and physical activity patterns during adolescence related to radial bone mass of white college-age females? Osteoporosis Int. 2:232-240.

20. Lloyd, T., N. Rollings, M.B. Andon, L.M. Demers, D.F. Eggli, K. Kiselhorst, H. Kulin, J.R. Landis, J.K. Martel, G. Orr, and P. Smith. 1992. Determinants of bone density in young women. I. Relationships among pubertal development, total body bone mass, and total body bone density in premenarchal females. J. Clin. Endocrinol. \& Metab. 75:383-387.

21. Ruiz, J.C., C. Mandel, and M. Garabedian. 1995. Influence of spontaneous calcium intake and physical exercise on the vertebral and femoral bone mineral density of children and adolescents. J. Bone Miner. Res. 10:675-682.

22. Katzman, D.K., L.K. Bachrach, D.R. Carter, and R. Marcus. 1991. Clinical and anthropometric correlates of bone mineral acquisition in healthy adolescent girls. J. Clin. Endocrinol. Metab. 73:1332-1339.

23. Kröger, H., A. Kotaniemi, P. Vainio, and E. Alhava. 1992. Bone densitometry of the Spine and Femur in Children by Dual-Energy X-ray Absorptiometry. Bone Miner. 17:75-85.

24. Grimston, S.K., K. Morrison, J.A. Harder, and D.A. Hanley. 1992. Bone mineral density during puberty in Western Canadian children. Bone Miner. 19: 85-96.

25. Kröger, H., A. Kotaniemi, L. Kröger, and E. Alhava. 1993. Development of bone mass and bone density of the spine and femoral neck - a prospective study of 65 children and adolescents. Bone Miner. 23:171-182.

26. Young, D., J.L. Hopper, C.A. Nowson, R.M. Green, A.J. Sherwin, B. Kaymakci, M. Smid, C.S. Guest, R.G. Larkins, and J.D. Wark. 1995. Determinants of bone mass in 10- to 26-year-old females: A twin study. J. Bone Miner. Res. 10:558-567.

27. Carrié, A. L., and J. P. Bonjour. 1995. Osteoporosis as a pediatric problem. Pediatr. Clin. North Am. 42:811-824.

28. Johnston, C.C., J.Z. Miller, C.W. Slemenda, T.K, Reister, S. Hui, J.C Christian, and M. Peacock. 1992. Calcium supplementation and increases in bone mineral density in children. N. Engl. J. Med. 327:82-87.

29. Lloyd, T., M.B. Andon, N. Rollings, J.K. Martel, J.R. Landis, L.M. Demers, D.F. Eggli, K. Kieselhorst, and H.E. Kulin. 1993. Calcium supplementation and bone mineral density in adolescent girls. JAMA. 270:841-844. 
30. Lee, W.T.K., S.S.F. Leung, S.H. Wang, Y.C. Xu, W.P. Zeng, J. Lau, S.J. Oppenheimer, and J.C.Y. Cheng. 1994. Double-blind, controlled calcium supplementation and bone mineral accretion in children accustomed to a low-calcium diet. Am. J. Clin. Nutr. 60:744-750.

31. Dawson-Hughes, B., G. E. Dallal, E. A. Krall, L. Sadowski, N. Sahyoun, and S. Tannenbaum. 1990. A controlled trial of the effect of calcium supplementation on bone density in postmenopausal women. N. Engl. J. Med. 323: 878-883.

32. Theintz, G., B. Buchs, R. Rizzoli, D. Slosman, H. Clavien, P.C. Sizonenko, and J.P. Bonjour. 1992. Longitudinal monitoring of bone mass accumulation in healthy adolescents: Evidence for a marked reduction after 16 years of age at the levels of lumbar spine and femoral neck in female subjects. $J$. Clin. Endocrinol. Metab. 75:1060-1065.

33. Katzman D.K., L.K. Bachrach, D.R. Carter, and R. Marcus. 1991. Clinical and anthropometric correlates of bone mineral acquisition in healthy adolescent girls. J. Clin. Endocrinol. Metab. 73:1332-1339.

34. Carter D.R., M.L. Bouxsein, and R. Marcus. 1992. New approaches for interpreting projected bone densitometric data. J. Bone Miner. Res. 7:137-145.

35. National Institutes of Health. 1994. Optimal calcium intake. NIH Consensus statement 12:1-31.

36. Gilsanz, V., T.F. Roe, J. Antunez, M. Carlson, M.L. Duarte, and W.G. Goodman. 1991. Effect of dietary calcium on bone density in growing rabbits. Am. J. Physiol. 260:471-476.

37. Holbrook T.L., E. Barrett-Connor, D.L. Wingard. 1988. Dietary calcium and risk of hip fracture: 14-year prospective population study. Lancet. ii: 1046-1049.
38. Matkovic V., D. Fontana, C. Tominac, P. Goel, C.H. Chesnut. 1990. Factors that influence peak bone mass: a study of calcium balance and the in heritance of bone mass in adolescent females. Am. J. Clin. Nutr. 52:878-888.

39. Matkovic, V., and R. P. Heaney. 1992. Calcium balance during human growth: evidence for threshold behavior. Am. J. Clin. Nutr. 55:992-996.

40. Forbes, R.M., K.E. Weingartner, H.M. Parker, R.M. Bell, and J.W. Erdman, Jr. 1979. Bioavailability to rats of zinc, magnesium and calcium in casein-, egg- and soy protein-containing diets. J. Nutr. 109:1652-1660.

41. Dawson-Hughes, B. 1991. Calcium supplementation and bone loss: a review of controlled clinical trials. Am. J. Clin. Nutr. 54:(suppl.)274-280.

42. Parfitt, A.M. 1994. The two faces of growth: Benefits and risks to bone integrity. Osteoporosis Int. 4:382-398.

43. Heaney, R.P. 1993. Nutritional factors in osteoporosis. Annu. Rev. Nutr. 13:287-316.

44. Kanis, J.A. 1994. Calcium nutrition and its implications for osteoporosis. Part I. Children and healthy adults. Eur. J. Clin. Nutr. 48:757-767.

45. Kanis, J.A. 1994. Calcium nutrition and its implications for osteoporosis Part II. After menopause. Eur. J. Clin. Nutr. 48:833-841.

46. Chevalley, T., R. Rizzoli, V. Nydegger, D. Slosman, C.H. Rapin, J.P. Michel, H. Vasey, and J.P. Bonjour. 1994. Effects of calcium supplements on femoral bone mineral density and vertebral fracture rate in vitamin-D-replete elderly patients. Osteoporosis Int. 4:245-252.

47. Clavien H., G. Theintz, R. Rizzoli, and J.-P. Bonjour. 1996. Does puberty alter dietary habits in adolescents living in a western society? J. Adolesc Health. 19:68-75. 